\title{
Early administration of Bifidobacterium breve to preterm infants: randomised controlled trial
}

Hiroyuki Kitajima, Yutaka Sumida, Ryuichiro Tanaka, Norikatsu Yuki, Hiroo Takayama, Masanori Fujimura

\begin{abstract}
Aim-To investigate the colonisation with Bifidobacterium breve of the bowels of very low birthweight (VLBW) infants.

Methods-The adverse effects of $B$ breve were examined in $66 \mathrm{VLBW}$ infants (preliminary study). A prospective randomised clinical study of 91 VLBW infants was also completed and these infants were followed up for three years. Precise viable bacterial counts of serial stool specimens were examined for the first eight weeks after birth in 10 infants. The colonisation rates of administered bacteria were examined using immunohistochemical staining of stool specimens with a $B$ breve specific monoclonal antibody.

Results-In the preliminary study there were no side effects attributable to the bacteria. Immunohistochemical staining of stool specimens showed that the colonisation rates of the administered bacteria were $73 \%$ at 2 weeks of age, but only $12 \%$ in the control group. Early administration of $B$ breve significantly decreased aspirated air volume from the stomach and improved weight gain.

Conclusions-B breve can colonise the immature bowel very effectively and is associated with fewer abnormal abdominal signs and better weight gain in VLBW infants, probably as a result of stabilisation of their intestinal flora and accelerated feeding schedules.

(Arch Dis Child 1997;76:F101-F107)
\end{abstract}

Keywords: Bifidobacterium breve; stool specimens; necrotising enterocolitis; very low birthweight.

Osaka Medical Center and Research Institute for Maternal and Child Health, Osaka, Japan H Kitajima

Y Sumida

M Fujimura

Yakult Central

Institute for

Microbiological

Research, Tokyo, Japan

R Tanaka

N Yuki

H Takayama

Correspondence to: Dr H Kitajim

Department of Neonatal

Medicine

Osaka Medical Center and

Research Institute for

Maternal and Child Health

Izumi, 590-02, Osaka,

Japan.

Accepted 11 November 1996 morbidity after resection of necrotic bowel, especially in small premature babies. ${ }^{5}$ Previous studies have suggested an association between the finding of enteric bacteria and necrotising enterocolitis..$^{6-9}$ Most of the episodes preceded rapid growth of a single strain of gut flora such as Klebsiella sp, Enterobacter sp, and Escherichia coli.

In our unit there were 15 cases of necrotising enterocolitis ${ }^{10}$ in low birthweight infants between 1981 and 1990. Necrotising enterocolitis (10/15: $67 \%$ of our cases) was associated with an abrupt overgrowth by a single strain of enteric bacteria in the few days following a change in formula during an increase in feeding. In these cases there was a rapid increase in the gas volume of gastric aspirate and acute and severe abdominal distension, and sometimes intestinal perforation. Rapid and vigorous fermentation by bacteria might be the cause. These observations suggested that early and adequate intestinal colonisation by Bifidobacteria instead of enteric bacteria might improve the clinical signs and might decrease the risk of necrotising enterocolitis and nosocomial infection by enteric bacteria in our neonatal intensive care unit. However, there have been few studies of administration of Bifidobacteria to newborn infants. ${ }^{11-13}$

\section{Methods}

Our neonatal intensive care unit admits between 200 and 300 babies every year, including about 100 very low birthweight (VLBW) infants. Half the VLBW infants weigh less than $1000 \mathrm{~g}$ at birth and about $90 \%$ of them are born in hospital.

Schedules of milk feeds for VLBW infants on our neonatal unit are as follows. The initiation of milk feeds is preceded by distilled water, after close observation of the infants' bowel sounds and gastric contents. When it is clear that water can be tolerated, expressed breast milk is started at $20 \mathrm{ml} / \mathrm{kg} /$ day. The daily rate of milk feeds is increased by between 10 and 20 $\mathrm{ml} / \mathrm{kg}$ until the total feeding volume reaches 80 to $100 \mathrm{ml} / \mathrm{kg} /$ day, after which there is a continuous daily increment of $20 \mathrm{ml} / \mathrm{kg}$, up to $150-180 \mathrm{ml} / \mathrm{kg} /$ day. After reaching full or constant feeding volume we gradually change the milk from expressed breast milk to formula feeds for premature babies, when breast milk proves insufficient for the baby or when formula feeds are considered better for weight gain. Expressed breast milk is collected in sterile glass bottles and frozen to $-40^{\circ} \mathrm{C}$ until use. A few millilitres of milk from one of every 
three to 10 bottles collected on the same day are cultured for bacterial counting. We use breast milk with less than $10^{6}$ colony forming units/ml of Staphylococcus epidermidis, or pasteurised breast milk with more than $10^{6}$ colony forming units $/ \mathrm{ml}$ of $S$ epidermidis but which has been heated at $58^{\circ} \mathrm{C}$ for 30 minutes. We never use breast milk from which other bacteria have been isolated.

PRELIMINARY STUDY

A preliminary study of the adverse effects of $B$ breve on preterm infants was carried out between 1987 and 1990. A total of 66 preterm infants were included after informed parental consent had been obtained. Bifidobacterium breve YIT4010 (BBG) was supplied as a freeze-dried powder in corn starch, containing about $10^{9}$ colony forming units/g dry weight (Yakult Honsya Co. Ltd., Tokyo, Japan). BBG was given as one gram of the powder per day in two or three divided doses. In this pilot study the effects of (a) early and short and (b) delayed and prolonged administration of $B$ breve were examined.

RANDOMISED TRIAL

We also carried out a randomised study of BBG between May 1990 and April 1991. A total of 97 VLBW infants were included. Two infants died at 5 and 16 days of age, respectively; three infants were transferred back to the referring hospital before they were 3 weeks old, and one girl was excluded after coarctation of aorta was diagnosed at 15 days of age. Ninety one infants were followed up for two months after birth to check their clinical course. Seventy were followed up for three years to examine their growth.

Entry criteria comprised a birthweight of under $1500 \mathrm{~g}$; those infants with major anomalies, severe asphyxia (1 minute Apgar score $<3$ ), and severe intrauterine growth retardation (<-3.0 SD) were excluded. After informed parental consent had been obtained, the infants were randomly allocated to receive $\mathrm{BBG}$ or distilled water (control infants).

One $\mathrm{ml}$ of the supernatant of BBG suspension with distilled water containing about $0.5 \times 10^{9}$ of live $B$ breve YIT4010 was initially given within the first 24 hours of life. The use of supernatant BBG suspension was instituted because of the adverse effect of corn starch aggregates in this regimen found in our preliminary study. This was given once a day from the initiation of milk feeds for 28 days. Meconium and stools from infants were collected for aerobic bacterial culture once a week for eight weeks. Part of each stool specimen was stored at $-40^{\circ} \mathrm{C}$. Colonisation by BBG was confirmed in each frozen sample by Gram staining and by an immunohistochemical method using a BBG specific monoclonal antibody.

The stools of 10 infants were examined to check all live bacterial counts for eight successive weeks after birth. Only one control infant was transferred to the referring hospital at 4 weeks of age. Bacterial cultures were started within 24 hours of sample collection-these

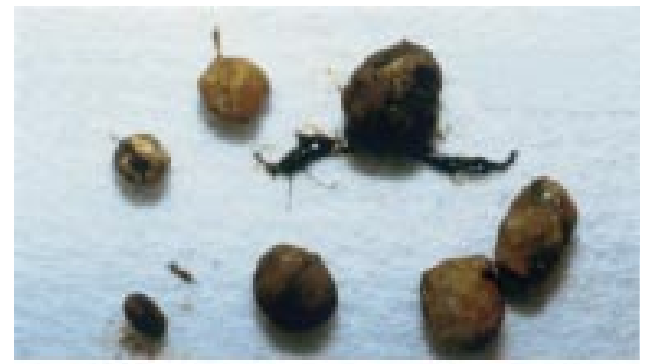

$A$

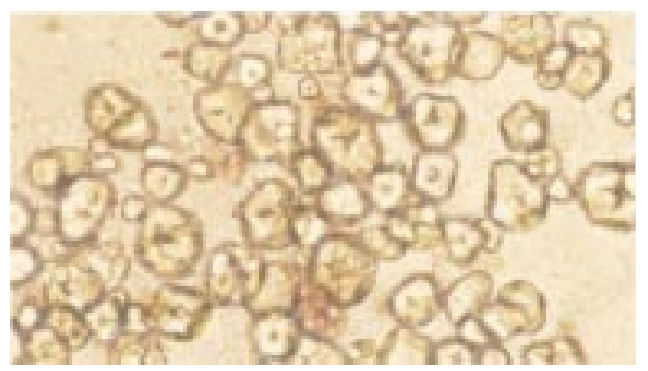

$B$

Figure 1 Corn starch aggregates in stool specimen of extremely low birthweight infant (24.4 weeks, $616 \mathrm{~g}$, female): (A) corn starch aggregates in stool specimen; (B) aggregates broken in distilled water ( $\times 400$ magnification).

had been cooled in an ice box before culture. The faecal microflora were investigated using anaerobic roll tube methods. ${ }^{14}$ In brief, the culture media used were: MVLG; MVLG-KV containing kanamycin $(80 \mathrm{mg} / \mathrm{l})$ and vancomycin (1.0 mg/l); MPN; and CW (Nissui, Japan), and these were used for counting total bacteria, Bacteroideae, Bifidobacteria, and lecithinase positive Clostridia, respectively. A TOS agar plate with the addition of carbenicillin (1.0 $\mathrm{mg} / \mathrm{l})$, specifically prepared for selective isolation of administered $B$ breve and LBS (BBL, USA) for counting lactobacilli, was cultivated anaerobically. Aerobic agar plates of DHL (Nissui, Japan), COBA (BBL, USA), Staphylo 110 (Nissui, Japan), Candida GS and NAC (Eiken, Japan) were used for counting enterobacteriaceae, enterococci, staphylococci, Candida and Pseudomonas species, respectively.

IMMUNOHISTOCHEMICAL STAINING

A BBG specific monoclonal antibody conjugated with colloidal gold particles was kindly provided by the Yakult Central Institute. It reacted with BBG and two other strains of $B$ breve, but not with three other similar ATCC strains and four other strains from clinical isolates. It did not cross react with other species of bacteria such as $B$ adolescentis, $B$ infantis, $B$ longum, $B$ bifidum, $B$ animalis, Lactobacillus paracasei, $L$ acidophilus, Lactococcus lactis, $L$ plantalum, Streptococcus thermophilus, $S$ salivarius, Enterococcus faecium, E faecalis, Bacillus subtilis, Bacteroides melaninogenicus, or $E$ coli.

Five $\mu \mathrm{l}$ of $1 \%(\mathrm{w} / \mathrm{v})$ freeze dried faecal samples homogenated with phosphate buffered saline were applied to a nitrocellulose membrane (Hybond-C, Amersham, UK) and dried in air. The membranes were placed into blocking solution (Block ace, Dainippon Pharmaceutical Company Ltd, Japan) at $4^{\circ} \mathrm{C}$ overnight. After washing the membranes three 

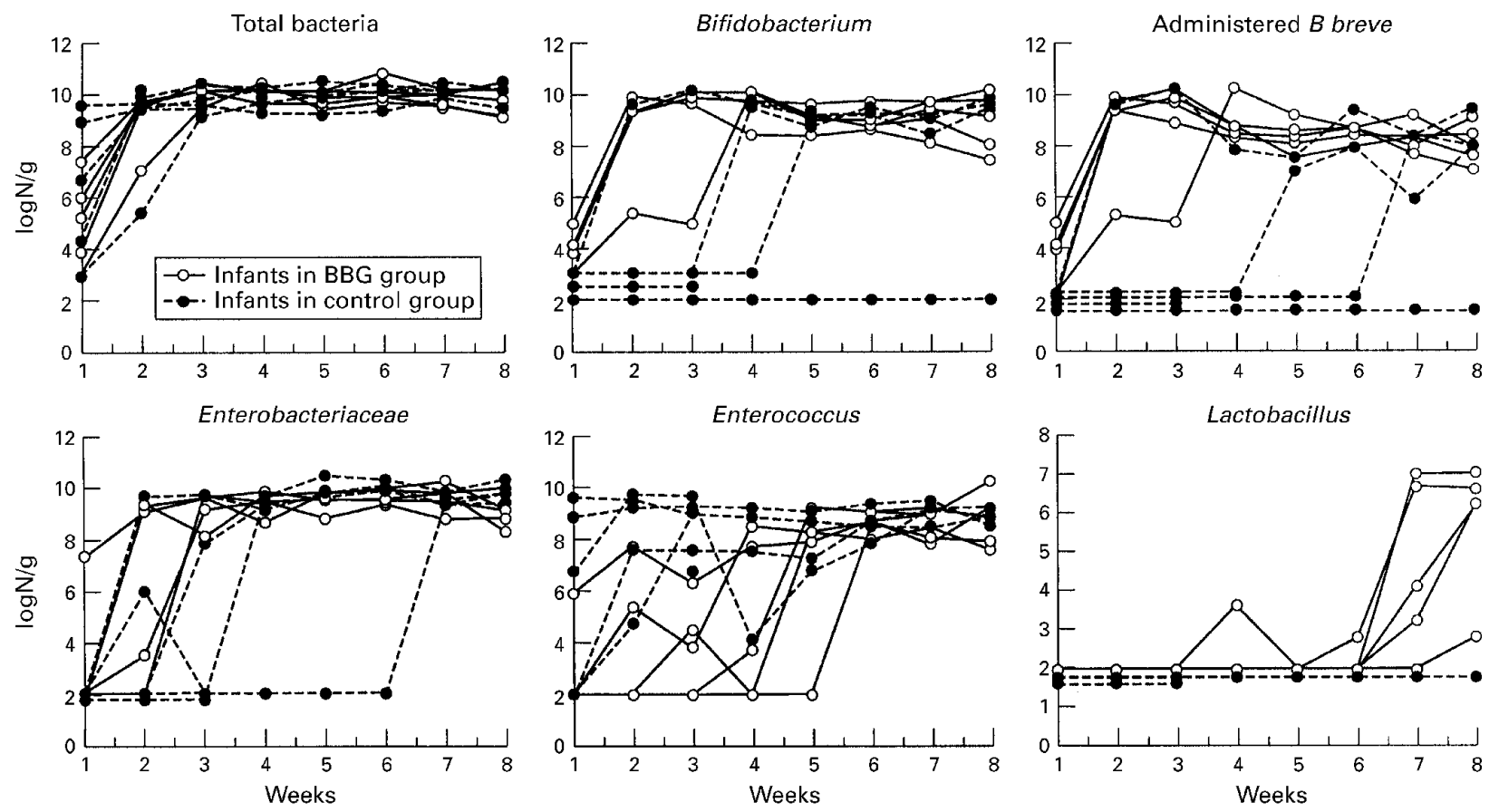

Figure 2 Bacterial counts from stool specimens from each infant.

times with phosphate buffered saline containing $0.05 \%$ Triton X-100 (Sigma, USA), they were exposed to $10 \mu \mathrm{l}$ of colloidal gold labelled $B$ breve specific mouse monoclonal antibody solution and kept for 10 minutes at room temperature. A positive reaction showed a faint red colour.

Clinical data were collected from each infant every day until 28 days of life and once a week until 9 weeks of life. Apnoea was defined as absence of breathing for 20 seconds.

Clinical data were analysed using the unpaired $t$ test and the Mann-Whitney $\mathrm{U}$ test. The data in the preliminary study are given as mean (1SD).

\section{Results}

PRELIMINARY OPEN STUDY

The participants comprised 16 infants (28.3 (3.0) weeks of gestation, 1052 (328) g) given early and brief treatment and 50 infants $(27.2$ (2.9) weeks of gestation, 860 (2340 g) given late and prolonged treatment. Early treatment was started within 7 days of life, before feeding, and lasted for seven days (median 5, range 1-7) at most. Late treatment was started after 7 days of life and lasted for more than seven days (median 14, range 7-48). Of the infants who

Table 1 Profiles of infants of the study groups *

\begin{tabular}{lll}
\hline & Controls & BBG administered \\
\hline No of cases & 46 & 45 \\
Sex (M/F) & $24 / 22$ & $25 / 20$ \\
No of SGA infants & 5 & 7 \\
Gestation (w) & $28.2(2.1)$ & $28.3(2.3)$ \\
Birth weight (g) & $1026(205)$ & $1026(241)$ \\
IPPV (days) & $3[0-163]$ & $4[0-244]$ \\
Duration of antibiotics & & $7.5[0-20]$ \\
$\quad$ days) & $7[0-28]$ \\
Doses of indomethacin & 55 & 40 \\
\hline
\end{tabular}

* Values represent mean (SD) or median [range]. BBG: administered Bifidobacterium breve, SGA: small for gestational age (<-1.5 SD), IPPV: intermittent positive pressure ventilation. received late treatment, two extremely preterm babies (a boy of 25.9 weeks, $770 \mathrm{~g}$, who received $3 \mathrm{~g}$ of BBG/day for 6 days and $1 \mathrm{~g} /$ day for 7 days; a girl of 24.4 weeks, $616 \mathrm{~g}$, who received $1 \mathrm{~g} /$ day for 30 days) had mild functional ileus shown by the presence of undigested corn starch aggregates in the stool (fig 1). Subsequently, the supernatant BBG suspension in distilled water $(1 \mathrm{~g}$ of BBG in $3 \mathrm{ml}$ of water) was used every time. There were no other adverse effects from BBG itself.

\section{COLONISATION PATTERN OF BBG AND OTHER} BACTERIA IN VLBW INFANTS

The mean $\log _{10}$ viable bacterial counts of BBG and other bacteria for 10 infants are shown in fig 2. The group given BBG had been colonised within 2 weeks of age, except for one whose delay in colonisation by BBG was attributed to intravenous antibiotics until 17 days of life. Rapid proliferation of BBG was seen at 4 weeks of age after antibiotic treatment had stopped. In contrast, administered $B$ breve took more than 4 weeks to colonise in two of the control babies. Early growth of BBG were detected in one control infant. This colonisation of BBG in the control infants suggested the growth of a cross contaminated BBG. During this study only one strain of $B$ infantis was isolated as a resident Bifidobacterium in infants in neonatal intensive care, particularly in the special care unit, and no other strain of $B$ breve except for $\mathrm{BBG}$ had been isolated. $B$ infantis was isolated from only one of the control infants after 4 weeks of age, while he was being cared for in the special care unit.

The numbers of Bifidobacterium were higher than those of enterobacteriacae for the first three weeks. Enterobacteriaceae had grown faster in infants of the BBG group than in those of the control group. But once enterobacteriaceae had colonised the control infants, the 
Table 2 Colonisation of BBG in infants of the study

\begin{tabular}{|c|c|c|c|c|c|c|c|c|c|c|}
\hline \multirow[b]{3}{*}{ Gestational weeks } & \multicolumn{5}{|c|}{ Controls } & \multicolumn{5}{|c|}{$B B G$ administered } \\
\hline & \multirow[b]{2}{*}{$N$} & \multicolumn{3}{|c|}{ Weeks after birth } & \multirow[b]{2}{*}{ (\% colonised) } & \multirow[b]{2}{*}{$N$} & \multicolumn{3}{|c|}{ Weeks after birth } & \multirow[b]{2}{*}{ (\% colonised) } \\
\hline & & 2 & 4 & 6 & & & 2 & 4 & 6 & \\
\hline$<26$ & 2 & 0 & 0 & 0 & $0(0 \%)$ & 5 & 1 & 2 & 1 & $4(80 \%)$ \\
\hline $26-28$ & 12 & 1 & 3 & 2 & $6(50 \%)$ & 15 & 11 & 0 & 2 & $13(87 \%)$ \\
\hline$>28$ & 11 & 2 & 1 & 2 & $5(45 \%)$ & 13 & 12 & 1 & 0 & $13(100 \%)$ \\
\hline Total & 25 & 3 & 4 & 4 & $11(44 \%)$ & 33 & 24 & 3 & 2 & $29(91 \%)$ \\
\hline Accumulated number & & 3 & 7 & 11 & & & 24 & 27 & 29 & \\
\hline$\%$ Colonised & & $12 \%$ & $28 \%$ & $44 \%$ & & & $73 \%$ & $82 \%$ & $91 \%$ & \\
\hline
\end{tabular}

Table 3 Weekly change of aspirated air volume from stomach, frequency of vomiting and apnoea *

\begin{tabular}{|c|c|c|c|c|c|c|c|c|c|c|}
\hline & \multicolumn{6}{|c|}{ Mean aspirated air volume ml/infant/week } & \multirow{2}{*}{\multicolumn{2}{|c|}{$\begin{array}{l}\text { Vomiting } \\
\text { times/group/week }\end{array}$}} & \multirow{2}{*}{\multicolumn{2}{|c|}{$\begin{array}{l}\text { Apnoea } \\
\text { times/group/week }\end{array}$}} \\
\hline & \multicolumn{2}{|c|}{$23-25 w$} & \multicolumn{2}{|c|}{$26-28 w$} & \multicolumn{2}{|c|}{$29-33 w$} & & & & \\
\hline & $C T L$ & $B B G$ & $C T L$ & $B B G$ & $C T L$ & $B B G$ & $C T L$ & $B B G$ & $C T L$ & $B B G$ \\
\hline Number of cases & 8 & 8 & 21 & 19 & 17 & 19 & 46 & 44 & 29 & 29 \\
\hline 1st week & 24 & 17 & 93 & 79 & 131 & 151 & 10 & 2 & 134 & 226 \\
\hline 2nd week & 60 & 48 & $146+$ & $95+$ & 133 & 109 & 41 & 28 & 727 & 467 \\
\hline 3rd week & 83 & 70 & 134 & 121 & 131 & 110 & 70 & 28 & 582 & 445 \\
\hline 4 th week & 99 & 92 & 127 & 91 & 130 & 89 & 36 & 19 & 368 & 196 \\
\hline Total & 267 & 226 & $495 \dagger$ & $385+$ & 511 & 435 & 163 & 77 & 1811 & 1334 \\
\hline
\end{tabular}

^ CTL means the control group and BBG means the BBG administered group. Frequency of apnoea was compared in the infants of less than 10 days' IPPV. $+\mathrm{P}<0.05$.

bacterial counts were higher than those in the infants of the administered group. The growth of Enterococcus sp was suppressed by BBG for four weeks, but the growth of Lactobacillus sp seemed to increase rapidly from 7 weeks of age in infants of the administered group. Other anaerobic bacteria such as Bacteroides $\mathrm{sp}$ or Clostridium sp were not isolated in these 10 infants. There was no change in growth patterns of other bacteria such as Staphylococcus, Pseudomonas, and Candida in infants who received BBG.

RANDOMISED CONTROLLED TRIAL

Table 1 shows the profile of both groups in the randomised study. There were no differences. The precise details of colonisation by BBG were assessed in 58 of 91 infants (64\%). This study revealed colonisation patterns of admin-

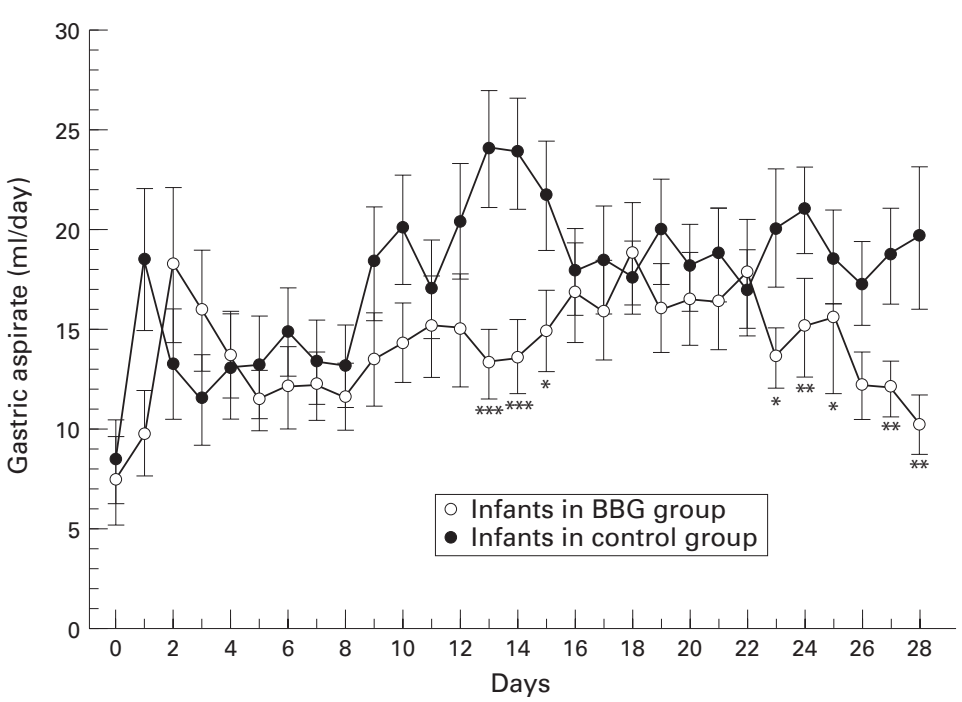

Figure 3 Daily changes in aspirated air volume from the stomach. Bars represent mean (SEM): ${ }^{\star \star \star} P<0.001 ;{ }^{\star \star} P<0.02 ;{ }^{\star} P<0.05$. istered $B$ breve in infants of various gestations (table 2). Their colonisation rates were $73 \%$ at 2 weeks and $91 \%$ at 6 weeks of age in the administered group, but $12 \%$ and $44 \%$ in the control group, respectively. The cumulative colonisation rates were $80 \%$ (23-25 weeks), $87 \%$ (26-28 weeks), and $100 \%$ (29-33 weeks) in the administered group, but $0 \%$ (23-25 weeks), $50 \%$ (26-28 weeks), and 45\% (29-32 weeks) in the control group. In the administered group, BBG had colonised at 2 weeks and grew rapidly, especially in infants of later gestation, but the colonisation rate of BBG was slower in the infants of shorter gestations, especially for those less than 26 weeks of gestation.

Three infants were poorly colonised by BBG six weeks after birth among 33 infants in the administered group whose stools were checked. All three infants had been given antibiotics for 10 days or more $(10,35$, and 36 days, respectively). The infant who had been treated with antibiotics for 10 days had only had 10 days of expressed breast milk. The others had been breast fed for about four weeks. These babies were also immature and under 28 weeks of gestation.

CLINICAL EFFECTS OF BBG ADMINISTRATION ON PRETERM INFANTS

The clinical effects of BBG administration to preterm infants are shown in the table 3. Mean aspirated air volume from the stomach in each infant between 25 and 28 weeks of gestation was significantly less in the administered group in the first four weeks, especially in the second week, although there were no differences in the time lapse between starting feeding and body weight gain between either group. Figure 3 shows daily changes in gas volumes of gastric aspirates in both groups. The BBG group gradually increased and then decreased gas 
Table 4 Profiles of infants of BBG colonised and not colonised ${ }^{\star}$

\begin{tabular}{lll}
\hline & BBG not colonised & BBG colonised \\
\hline No of cases & 20 & 26 \\
No of BBG administered & 3 & 23 \\
Sex (M/F) & $10 / 10$ & $11 / 15$ \\
No of SGA infant & 2 & 4 \\
Gestation (w) & $28.5(1.7)$ & $28.9(2.0)$ \\
Birth weight (g) & $1049(196)$ & $1117(191)$ \\
IPPV (days) & $4.5[0-47]$ & $3[0-44]$ \\
Duration of antibiotics (days) & $8[0-24]$ & $7[0-21]$ \\
Doses of indomethacin & $25 \dagger$ & $8 \dagger$ \\
\hline
\end{tabular}

$\star$ Values represent mean (SD) or median [range].

$\dagger \mathrm{p}=0.0621$.

BBG: administered Bifidobacterium breve, SGA: small for gestational age (<-1.5SD), IPPV: intermittent positive pressure ventilation.

volume, but the control group this rapidly increased between 8 to 14 days and slowly decreased after the peak. Vomiting and apnoea gradually became more common between 2 and 3 weeks of life. These were slightly less common in the administered group, but this difference was not significant.

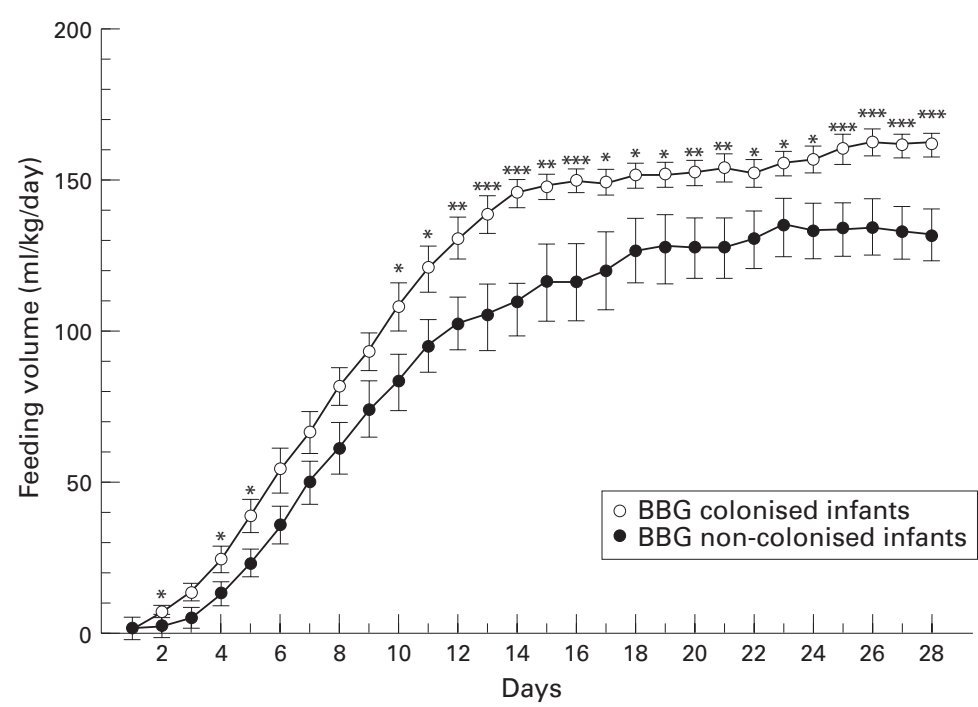

Figure 4 Daily changes in feeding volume: bars represent mean (SEM). ${ }^{\star \star} P<0.001 ;{ }^{\star \star} P<0.02 ;{ }^{\star} P<0.05$.

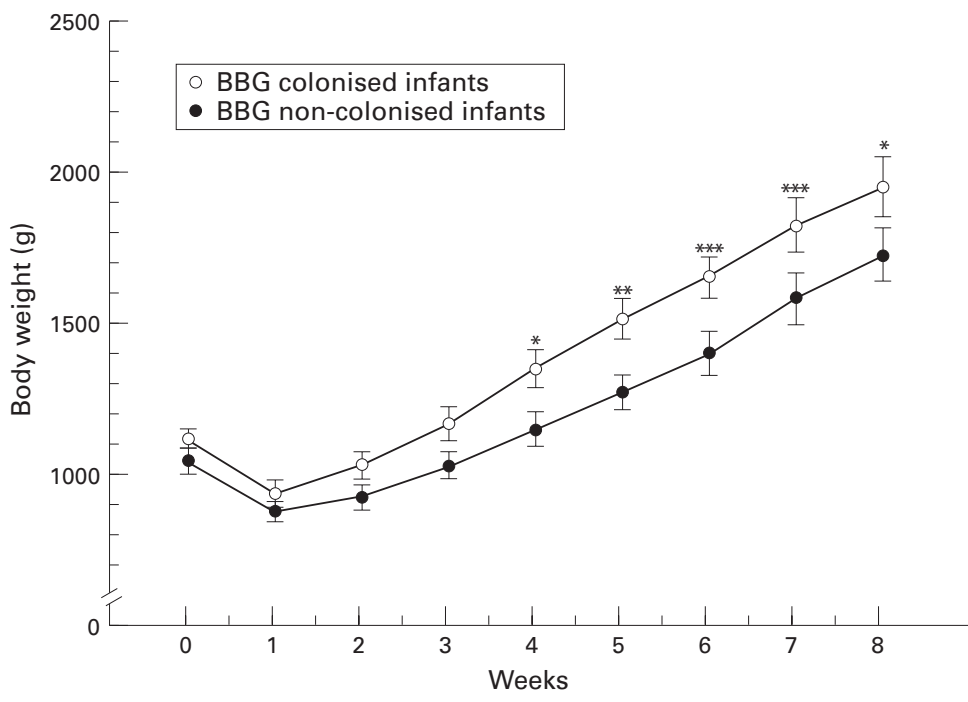

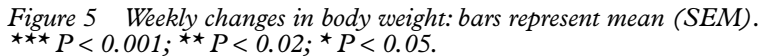

CLINICAL EFFECTS OF BBG ON FULLY COLONISED INFANTS

To investigate the effects of actual intestinal colonisation of BBG, 58 study infants whose serial stools had been tested by immunochemical staining of BBG were divided into two groups (table 4). Colonised infants were grouped according to colonisation by BBG (more than $10^{9}$ colony forming units/g) within 2 weeks of age and non-colonised infants were defined as those not colonised by BBG until 6 weeks of age. Their characteristics are shown in table 4. Colonised infants were given fewer doses of indomethacin than non-colonised infants but this difference was not significant. There was also less gas accumulation in the stomach, and less vomiting among BBG colonised infants. Colonised infants also established earlier feeding and had greater feeding volume afterwards (fig 4). Weight gain was also significantly greater in the colonised infants between 4 and 8 weeks of life (fig 5). Better growth pattern in the administered group tended to persist for 18 months, but this was not significant (data not shown).

\section{Discussion}

The BBG strain of $B$ breve was chosen because it is the most common species of Bifidobacterium in breastfed infants and the most well known of the Bifidus flora. ${ }^{15}$ It was isolated from a healthy newborn infant as a probiotic, and is considered to be a "live" microbial feed supplement that beneficially affects the host by improving intestinal microbial balance. ${ }^{16}$ Furthermore, Bifidus flora is rarely established in early life and may be delayed, even if very low birthweight infants can be colonised. ${ }^{3}$ Recently Akiyama et al reported that $B$ breve had a much stronger affinity for immature bowels than $B$ longum. ${ }^{12}$ The safety of BBG was tested in 130 children aged 6 months to 15 years who were diagnosed as having Campylobacter enteritis ${ }^{17}$ and in 15 patients with intractable diarrhoea aged 1 month to 15 years. ${ }^{18}$ Both studies reported that BBG showed no adverse effects and improved intestinal microflora by eradicating Campylobacter ${ }^{17}$ or Candida and Enterococcus ${ }^{18}$ in those patients. However, there has been a case report of meningitis in an infant ${ }^{19}$ attributed to $B$ breve ss breve that was resistant to penicillins and cephalosporins. By contrast, BBG is an easily controlled strain of $B$ breve, because it is very sensitive to penicillins and cephalosporins but not streptomycin.

In the randomised study, the colonisation of BBG in very low birthweight infants was generally established within the first two weeks of life when administered early. The bacterial count also revealed that BBG was fully established within the first two weeks and that enterobacteriaceae grew to the same levels as Bifidobacterium in the BBG administered group after three weeks. The growth of enterobacteriaceae was associated with formula feeding because all five infants tested had changed from expressed breast milk to formula feed for premature babies at 3 weeks of age. Yoshioka et $a l^{20}$ reported full term infants at 1 month of age in whom Bifidobacterium was highly prevalent 
and suppressed the growth of enterobacteriaceae and other bacteria at a ratio of 100 to 1 in the breastfed infants, but in the bottle-fed infants the levels of Bifidobacterium and other coliform bacteria were one tenth and tenfold that of breastfed infants, respectively.

There have not been many studies on the administration of bifidobacteria or lactobacilli to newborn infants. Bennet et al found that transient colonisation by these species was detected in newborn infants after treatment with antibiotics; no side effects were noted. ${ }^{11}$ Miller et al gave Lactobacillus GG to 20 preterm infants with a gestational age of 33 weeks or less. The bacteria were well tolerated and colonised the bowel of premature infants. However, colonisation with Lactobacillus GG did not reduce the faecal reservoir of potential pathogens and there was no evidence that colonisation had any positive clinical benefit on this particular group of infants. ${ }^{21}$ The same group reported the effects on gut fermentation of feeding premature infants with Lactobacillus GG. It had no obvious adverse effects on nutritionally important short chain fatty acids. They found a small increase in ethanol excretion in faecal samples from treated babies which was probably not clinically important. ${ }^{22}$ These studies showed that bifidobacteria or lactobacilli can colonise the gut of newborn infants, even when they are preterm. However, there were no detectable clinical benefits.

Akiyama et al reported the effects of oral administration of $B$ breve on the development of intestinal microflora in extremely premature infants. They gave $B$ breve to five extremely premature infants who were colonised by the administered $B$ breve within 2 weeks of age. By contrast, colonisation by $B$ breve was delayed for more than six weeks in the five control babies. No side effects were noted with this regimen. ${ }^{13}$ These colonisation patterns of $B$ breve were very similar to those of our own randomised trial. Their regimen, however, contained dextrin powder instead of corn starch. The authors recommended using dextrin that can be hydrolysed by preterm infants. ${ }^{23}$ Before our randomised study of BBG, aggregates of corn starch were associated with mild functional ileus in two extremely premature infants. This suggested that extremely immature babies under 25 weeks of gestation cannot hydrolyse corn starch sufficiently well.

In our randomised trial of BBG, we used a specific monoclonal antibody to BBG. The rate of cross infection of the bacteria used in the control group was about $12 \%$ in two weeks and $44 \%$ in six weeks. This contamination occurred in spite of strict hand washing with an iodine solution before and after touching the babies. It is very difficult not only to assess if live bacteria have randomly colonised each infant in both groups and but also to examine the viable bacterial count in each stool specimen. A specific monoclonal antibody to BBG was very useful for the detection of BBG in the stool and gave us semiquantitative data concerning the colonisation of BBG in infants. This technique could be applied to other randomised trials using live bacteria.
BBG administration caused only a slight change in the intestinal colonisation pattern in our patients. But it is important to check for vitamin $\mathrm{K}$ deficiency in infants who might have only Bifidobacterium flora instead of enterobacteriaceae. One of a set of twins (24 weeks of gestation) out of about 500 VLBW infants receiving $\mathrm{BBG}$ showed a transient prolonged partial thromboplastin time at 30 days of life. His stool cultures revealed Bifidobacterium flora alone, and he may have been vitamin $\mathrm{K}$ deficient, because bifidobacteria cannot generally produce vitamin $\mathrm{K} .{ }^{24}$

BBG treatment with breast feeding is a natural and effective approach for the stabilisation of intestinal microflora in preterm infants. In recent years we routinely start breast feeding in preterm infants and then change to formula feeds after the establishment of full feeding in each infant. Lucas and Cole reported a low incidence of necrotising enterocolitis in infants fed breast milk. ${ }^{25}$ We have had no cases of necrotising enterocolitis in babies fed breast milk only. Breast feeding would also encourage the growth of Bifidobacterium. This supports the view that breast feeding prevents necrotising enterocolitis.

We thank Dr Weindling for his helpful comments, and we are grateful to Dr T Takeuchi and the nursing staff of our neonatal intensive care unit for their help.

1 Goldmann DA, Leclair J, Macone A. Bacterial colonization of neonates admitted to an intensive care environment. $\mathcal{F}$ Pediatr 1978;93:288-93.

2 Stark PL, Lee A. The bacterial colonization of the large bowel of pre-term low birth weight neonates. I Hyg ;89.59-67.

3 Sakata H, Yoshioka H, Fujita K. Development of the intestinal flora in very low birth weight infants compared to normal full-term newborns. Eur F Pediatr 1985;144:18690.

4 Jarvis WR. Epidemiology of nosocomial infections in pediatric patients. Pediatr Infect Dis 1987;6:344-51.

5 Kliegman RM, Fanaroff AA. Neonatal necrotizing enterocolitis. $N$ Engl f Med 1984;310:1093-103.

6 Hoy C, Miller MR, Mackay P, Godwin PGR, Langdale V, Levene MI. Quantitative changes in faecal microflora preceding necrotising enterocolitis in premature neonates. Arch Dis Child 1990;65:1057-9.

7 Bell MJ, Shackelford P, Feigin RD, Ternberg JL, Brotherton T. Epidemiologic and bacteriologic evaluation of neonatal necrotizing enterocolitis. $\mathcal{F}$ Pediatr Surg 1979;14:1-4.

8 Frantz ID, L'Heureux P, Engel RR, Hunt CE. Necrotizing enterocolitis. F Pediatr 1975;86:259-63.

9 Speer ME, Taber LH, Yow MD, Rudolph AJ, Urteaga J, Waller S. Fulminant neonatal sepsis and necrotizing enterocolitis associated with a 'non-enteropathogenic' strain of Escherichia coli. F Pediatr 1976;89:91-5.

10 Kubota A, Imura K, Fujimura M, Hata S, Hasegawa T, Kobayashi $\mathrm{T}$, et al. Necrotizing enterocolitis of neonates born in a large perinatal referring center. Fpn f Pediatr Surg 1992;28:1334-41.

11 Bennet R, Nord CE, Zetterström R. Transient colonization of the gut of new born infants by orally administered bifido-bacteria and lactobacilli. Acta Paediatr 1992; 81:784-7.

12 Akiyama K, Shimada M, Ishizeki S, Takigawa I, Imura S, Yamauchi K, et al. Effects of administration of Bifidobacterium in extremely premature infants; development of intestinal microflora by orally administered Bifidobacteintestinal microflora by orally administered BifidobacteActa Neonatol faponica 1993;30:257-63.

13 Akiyama K, Hosono S, Takahashi E, Ishizeki S, Takigawa I, Imura $\mathrm{S}$, et al. Effects of oral administration of Bifidobacterium breve on development of intestinal microflora in extremely premature infants. Acta Neonatol faponica 1993; 30:130-7.

14 Tanaka R, Mutai M. Improved medium for selective isolation and enumeration of Bifidobacterium. Appl Environ Microbiol 1980;40:866-99.

15 Mitsuoka T, Kaneuchi C. Ecology of the bifidobacteria. Am f Clin Nutr 1977;30:1799-810.

16 Fuller R. Probiotics in man and animals: a review. $\mathcal{F}$ Appl Bacteriol 1989;66:365-78.

17 Tojo M, Oikawa T, Morikawa Y, Yamashita N, Iwata S, Sato $\mathrm{Y}$, et al. The effects of Bifidobacterium breve administration of Campylobacter enteritis. Acta Paediatr $\mathfrak{f p}_{p}$ 1987;29:160-7. 
18 Hotta M, Sato Y, Iwata S, Yamashita N, Sunakawa K, Oikawa $\mathrm{T}$, et al. Clinical effects of bifidobacterium preparations on pediat

19 Hata D, Yoshida A, Ohkubo H, Mochizuki Y, Hosoki Y, Hata D, Yoshida A, Ohkubo H, Mochizuki Y, Hosoki $\mathrm{Y}$,
Tanaka $\mathrm{R}$, et al. Meningitis caused by Bifidobacterium in an infant. Pediatr Infect Dis f 1988;7:669-71.

20 Yoshioka H, Iseki K, Fujita K. Development and differences of intestinal flora in the neonatal period in breast-fed and bottle-fed infants. Pediatrics 1983;72:317-21.

21 Millar MR, Bacon C, Smith SL, Walker V, Hall MA. Enteral feeding of premature infants with Lactobacillus GG. Arch Dis Child 1993;69:483-7.
22 Stansbridge EM, Walker V, Hall MA, Smith SL, Miller MR, Bacon C, et al. Effects of feeding premature infants with Lactobacillus GG on gut fermentation. Arch Dis Child 1993;69:488-92.

23 Cicco R, Holzman IR, Brown DR, Becker DJ. Glucose polymer tolerance in premature infants. Pediatrics 1981;67:498-501.

24 Collins MD, Jones D. Distribution of isoprenoid quinone structural types in bacteria and their taxonomic implications. Microbiol Rev 1981;45:316-54.

25 Lucas A, Cole TJ. Breast milk and neonatal necrotising enterocolitis. Lancet 1990;336:1519-23. 